\title{
HABERMAS: OS FUNDAMENTOS DO ESTADO DEMOCRÁTICO DE DIREITO
}

Aylton Barbieri DURÃO ${ }^{1}$

- RESUMO: O estado democrático de direito constitui-se por meio de uma tensão interna entre direito e política, pois, além de suas funções próprias, uma vez que o direito deve regular os conflitos interpessoais ou coletivos de ação, enquanto a política deve elaborar os programas coletivos de ação, cada um deve desempenhar funções recíprocas para o outro, já que a política, como polo instrumental, deve dotar as normas jurídicas de capacidade de coação, enquanto o direito, como polo normativo, deve emprestar sua própria legitimidade para as decisões políticas. Para a fundamentação dos princípios do estado de direito, é necessário uma reconstrução intersubjetiva da soberania popular com base na teoria do discurso, segundo a qual a soberania não se encontra localizada em nenhum sujeito concreto, mas dispersa na ampla rede de comunicação que perpassa a esfera pública, na qual se forma o poder comunicativo, capaz de neutralizar o poder social dos grupos de pressão e formar uma opinião pública que orienta a tomada de decisões e o poder administrativo das instituições do estado de direito.

- PALAVRAS-CHAVE: Habermas; direito; política; discurso; poder.

Habermas obtém os direitos fundamentais, ou seja, os direitos subjetivos e os direitos políticos de participação e comunicação, que os cidadãos não têm outra opção senão atribuir-se reciprocamente, da perspectiva da socialização horizontal dos autores das normas jurídicas enquanto participantes nos discursos jurídicos, sem a intervenção do sistema político. Esta estratégia de dedução das normas jurídicas constitui um experimento mental, porque os direitos fundamentais, como quaisquer outras leis do or-

1 Doutor em Filosofia pela Universidade de Valladolid, Espanha, e professor do Departamento de Filosofia da Universidade Estadual de Londrina (UEL). Artigo recebido em 04/2009 e aprovado em 06/2009. 
denamento jurídico, somente podem ser aprovados e sancionados pelas instituições políticas do estado de direito. Isto, evidentemente, requer passar para o nível da socialização vertical, no qual já não são os próprios cidadãos no processo de autolegislação por meio dos discursos práticos que chegam a um consenso racional sobre seus direitos fundamentais, mas os cidadãos envolvidos com as estruturas políticas e jurídicas do estado de direito (HABERMAS, 1994, p. 166).

O estado de direito forma-se, tanto empírica como normativamente, mediante uma conexão interna entre direito e política. Começando pela perspectiva normativa, o sistema jurídico e o sistema político têm funções próprias, porém também cumprem funções recíprocas entre si na sociedade complexa. O sistema jurídico, a exemplo da moral, desempenha a função de coordenar a ação e solucionar os conflitos de ação entre os cidadãos, todavia, a moral racional pós-convencional tornou-se um saber que somente pode obrigar por meio da força frágil da convicção, enquanto o direito dispõe da capacidade de coagir os arbítrios privados. O sistema político, por outro lado, permite aos agentes realizar programas coletivos de ação, pois os cidadãos que interagem não somente divergem sobre a interpretação de valores e normas morais ou jurídicas, mas também definem metas de ação que transcendem a capacidade dos cidadãos isolados e precisam ser implementadas por meio de uma estrutura política que conjugue os esforços do grupo (HABERMAS, 1994, p. 179).

$\mathrm{O}$ direito e a política, por conseguinte, distinguem-se, em primeiro lugar, por suas funções próprias, porém, também por causa do modo com que ocorre, em seu interior, a tensão entre facticidade e validade. O direito é, antes de mais nada, um sistema normativo que lança mão da violência, na forma de coerção legalmente institucionalizada, exclusivamente para desempenhar sua função de coordenar a ação, mas esta coerção, em princípio, pode ser dispensada, por exemplo, quando os cidadãos cumprem a lei por respeito ou conviç̧ão; a política, por outro lado, é um sistema baseado no meio poder que dispõe da violência aprovada institucionalmente, até mesmo quando deve garantir o exercício da dominação legal (HABERMAS, 1994, p. 171).

Mas o nexo entre direito e política depende não apenas de que eles realizem a função própria de cada um, mas cumpram também funções recíprocas entre si, até mesmo como condição para que cada um possa executar sua função específica. O sistema jurídico precisa ser complementado pelo sistema político, pois a solução dos conflitos de ação depende da intervenção dos instrumentos da violência que são oferecidos pelo poder político; da mesma forma, o sistema político necessita da colaboração do sistema jurídico para estabelecer fins coletivos de ação, porque, por um lado, as instituições que compõem o sistema político somente se constituem por meio 
do direito e, por outro, a intervenção da política nos demais sistemas sociais, assim como no mundo da vida, efetua-se por meio do uso das normas jurídicas de ação (HABERMAS, 1994, p. 179).

O nexo interno entre direito e política pode ser descrito também empiricamente mediante a reconstrução da origem histórica do estado de direito. Habermas aceita a interpretação antropológica de Parsons sobre a evolução das estruturas políticas e jurídicas que começam com as sociedades organizadas por parentesco. Parsons introduz dois modelos para explicar a solução dos conflitos interpessoais (função própria do direito), assim como dois tipos de formação da vontade coletiva (função própria da política), que revelam o surgimento do nexo interno entre direito e política (HABERMAS, 1994, p. 173). Nas sociedades pré-estatais, as normas morais e jurídicas constituem um amálgama com os valores religiosos da comunidade, isto permite que se chegue a um consenso em caso de conflito de ação quando os agentes são orientados pelo entendimento, ou pode ser invocado por sacerdotes ou outras pessoas de prestígio com o propósito de realizar a arbitragem quando os agentes somente têm em consideração seus próprios interesses. Por outro lado, os programas, metas e fins coletivos podem ser estabelecidos com base na decisão proveniente da autoridade de pessoas ou famílias que gozam de prestígio suficiente para interpretar os valores derivados do fundo normativo e religioso ou pela formação de compromissos entre os interesses das partes litigantes que utilizam seu poder de pressão (HABERMAS, 1994, p.175-6).

A fusão empírica entre direito e poder político, que origina o Estado, ocorre em dois momentos. No primeiro, um membro de uma família influente assume as funções de intérprete da verdade revelada em cerimônias religiosas, juiz das causas entre sujeitos privados e líder de programas coletivos, convertendo-se em juiz-rei capaz de controlar o poder político, o qual se fundamenta no direito natural estabelecido pela autoridade de Deus, segundo a religião compartilhada por todos (HABERMAS, 1994, p. 180-1). O Estado propriamente dito, porém, somente se constitui em um segundo momento, quando surge uma burocracia estatal especializada em questões de administração pública e aplicação da justiça, capaz de implementar os programas políticos e a solução de conflitos de ação (HABERMAS, 1994, p. 181-2).

Por conseguinte, o estado de direito é o resultado da fusão, tanto empírica como normativa, entre direito e política. O direito e a política, contudo, constituem dois polos dentro do estado de direito, o que explica um novo sentido da tensão interna entre facticidade e validade, diferente da tensão que aparece para os destinatários das normas jurídicas e seus autores nos discursos jurídicos de fundamentação do sistema de direitos. Essa tensão interna entre facticidade e validade é explicada pela teoria da ação mediante a dupla possibilidade que tem o agente de agir segundo a razão estraté- 
gica ou a razão comunicativa e revela-se em três níveis: da norma jurídica, do sistema de direitos e do estado democrático de direito. Os destinatários experimentam a tensão interna entre facticidade e validade das normas jurídicas porque, por um lado, escolhem segui-las de acordo com a racionalidade estratégica, em cujo caso obedecem à lei simplesmente porque ela constitui um fato social que pode ser imposto por coerção e exige do agente empreender uma escolha racional em que reflete sobre os custos e benefícios de cumprir a lei ou infringi-la, ou, por outro lado, mediante a racionalidade comunicativa, que lhe permite avaliar a validade da lei, em cuja situação sente-se obrigado a cumpri-la por respeito à própria lei; essa duplicação da racionalidade inerente à sociedade complexa conduz também a uma duplicação do conceito de autonomia do direito, desconhecida no âmbito da moral, pois o destinatário da norma jurídica pode segui-la por meio de sua autonomia privada, quer dizer, do uso de sua liberdade subjetiva de ação, ou por meio de sua autonomia pública mediante a liberdade comunicativa, que demanda a busca cooperativa do entendimento; os autores do direito também observam essa tensão interna entre facticidade e validade, na medida em que percebem a duplicação do conceito de autonomia do direito e podem produzir as normas jurídicas segundo a escolha racional ou a busca recíproca de entendimento, o que gera o aparente paradoxo de explicar o surgimento da legitimidade a partir da legalidade.

A tensão entre facticidade e validade no estado de direito, por sua vez, revela-se por meio da cisão entre os polos poder, representado pela política, e normativo, constituído pelo direito. Habermas não tem dúvida sobre o caráter instrumental da política, que dispõe do meio poder para coordenar a ação, enquanto o direito não pode desfazer-se de seu papel normativo. A política permite ao estado de direito exercer a violência que subtraiu dos indivíduos privados, enquanto o direito oferece seu próprio meio para constituir o estado de direito e alimenta-se constantemente das relações de solidariedade provenientes do mundo da vida ou da fundamentação racional das questões problematizadas por meio dos discursos (HABERMAS, 1994, p. 171).

A tensão entre o polo poder e o polo normativo do estado de direito pode, contudo, ser deslocada para uma direção ou para outra. Se imperar a positividade do poder político, o estado de direito ameaça converter-se em simples exercício arbitrário do poder; em tal caso, a normatividade do direito se transformaria em pura legalidade utilizada em favor do exercício da dominação; mas, caso prevaleça a normatividade do direito, então, as instituições do estado de direito poderiam gerar as condições para a autolegislação democrática dos próprios cidadãos (HABERMAS, 1994, p. 208).

A introdução da tensão interna entre facticidade e validade no nível do estado de direito, procedente da conexão entre política e direito, permite a Habermas modificar significativamente seu ponto de vista com respeito ao 
sistema jurídico e à teoria do Estado. Começando com A reconstrução do materialismo histórico, de 1976, e culminando com Teoria da ação comunicativa, de 1981, Habermas explica o papel do Estado na sociedade moderna com base em sua teoria da ação comunicativa, a qual desenvolve uma concepção instrumental da política como um sistema funcional regido pelo meio poder (HABERMAS, 1995, p. 400-4). Seu modelo sociológico divide a sociedade complexa em dois níveis: um primeiro nível, constituído pelo mundo da vida, em que os agentes sociais orientam-se pela racionalidade comunicativa por meio da linguagem ordinária, usada por falantes que reivindicam pretensões de validade ilocutoriamente presentes no ato de fala, e um segundo nível, formado por sistemas sociais especializados em realizar funções que exigem dos agentes o comportamento estratégico motivado pelo êxito, entre os quais se destacam o mercado e a política. O mundo da vida, especializado na integração social, requer que os agentes coordenem suas ações pela solidariedade imersa na intersubjetividade do reconhecimento recíproco, enquanto os sistemas sociais, mercado e política, separam-se do mundo da vida e dispõem cada qual de uma lógica própria que orienta a conduta dos agentes. Os agentes sociais coordenam suas ações no mercado por intermédio do meio dinheiro e, na política, com base no meio poder. Portanto, para a teoria da ação comunicativa, a política surge como um sistema social no qual os agentes buscam estrategicamente exercer influência ou poder reciprocamente e que contribui juntamente com a economia e o direito para colonizar o mundo da vida e encolher o espaço para a racionalidade comunicativa.

Com base nessa concepção sistêmica, é possível explicar por que o Estado liberal e o Estado do bem-estar social converteram-se nas principais alternativas políticas da sociedade moderna. O Estado liberal fundamentase em uma sociedade centrada no sistema econômico, na qual os sujeitos privados utilizam sua liberdade subjetiva e contam somente com a livre competição para coordenar a ação entre si, o que exige um mercado isento de intervenções externas, que se autorregule e alcance o pleno emprego dos fatores de produção: trabalho e capital. O Estado do bem-estar, por outro lado, observa e critica o fracasso da autorregulamentação econômica, uma vez que o mercado provoca crises constantes, assim como gera uma desigualdade e injustiça material crescentes; em seu lugar, propõe um modo de bem-estar social que intervém no mercado para evitar as crises, assim como para compensar as desigualdades econômicas e sociais. As intervenções estatais, para compensar as crises econômicas e seus efeitos indesejáveis, além de caras, geram outras formas de crises, provocadas pelas exigências excessivas da burocracia, como o paternalismo e o assistencialismo; portanto, o Estado do bem-estar simplesmente desloca a crise do sistema econômico para o sistema político. Mas estas novas crises terminam 
por transferir-se de volta ao sistema econômico, uma vez que o custo dos programas de assistência social ocasiona o aumento da inflação e do desemprego, o que demanda, como solução, uma política neoliberal, que reduz as funções do Estado, a burocracia e o intervencionismo, fazendo recomeçar o ciclo apontado inicialmente. Consequentemente, o Estado liberal e o Estado do bem-estar social desenvolveram estratégias de descarga, as quais transladam o peso dos problemas do sistema econômico para o sistema político, e vice-versa, na medida em que deslocam as crises oscilantes de um sistema para o outro (HABERMAS, 1995, v. 2, p. 505-6).

Mas, além da competição entre o Estado liberal e o Estado do bem-estar social, com o respectivo incremento dos sistemas econômico e político, que constitui o que Habermas denomina o "dilema estrutural da sociedade complexa", a racionalidade estratégica, empregada por ambos os sistemas sociais, tem como efeito a colonização do mundo da vida, que ameaça despedaçar a capacidade de integração social, a qual, na sociedade complexa, dividida em sistemas funcionais, localiza-se na racionalidade comunicativa, realizada por meio da linguagem ordinária e utilizada pelos falantes no mundo da vida. A intromissão da política no mundo da vida implica, por exemplo, a redução da cidadania, a transformação dos cidadãos em clientes das burocracias estatais e a juridicização das relações sociais. A burocracia não constitui uma estrutura neutra em relação ao poder, pois transforma os cidadãos em clientes dos serviços do bem-estar social, geralmente já marginalizados pelo sistema econômico, o que implica acrescentar uma sobreexclusão aos indivíduos e grupos que se pretendia ajudar (HABERMAS, 1995, v. 2, p. 514-5).

Somente com a publicação, em 1985, do opúsculo "A nova intransparência", Habermas reconhece a necessidade de oferecer uma perspectiva para o beco sem saída da sociedade moderna. A nova intransparência resulta do aparente esgotamento das energias utópicas da modernidade em finais do século XX (HABERMAS, 1987, p. 143). Habermas considera que o desencantamento com respeito à modernidade provém do esgotamento do paradigma da sociedade do trabalho livre que guiou tanto a interpretação do Estado liberal como a bem-estarista (HABERMAS, 1987, p. 146). ${ }^{2}$ O liberalismo acreditou gerar o trabalho livre, na medida em que substituiu o trabalho servil e escravo pelo trabalho assalariado, no qual o trabalhador podia escolher livremente como vender sua força de trabalho, de acordo com o princípio da igualdade de oportunidades para todos, enquanto o socialismo observou que o trabalho livre exigiria o fim da mais-valia com a consequente

2 Trata-se de um neologismo resultante da tradução da palavra inglesa welfarism. 
distribuição coletiva dos produtos do trabalho na sociedade sem classes. A nova intransparência, contudo, desvanece-se tão logo se observa que o desencantamento do final do século XX não representa o esgotamento das energias utópicas, mas a extenuação da utopia do trabalho livre, a qual começa a ser substituída pela utopia da sociedade de comunicação livre (HABERMAS, 1987, p. 161-2).

O estudo sobre a nova intransparência, todavia, apenas indica que está ocorrendo uma mudança de paradigma, que se caracteriza pela formação de uma utopia da sociedade de comunicação livre, mas não explica como esta utopia, ao mesmo tempo, resulta e fomenta a transformação da sociedade moderna. Unicamente com a publicação do artigo "Soberania popular como procedimento", de 1988, Habermas esclarece como a tensão interna entre direito e política dentro do estado de direito permite mostrar a integração social na sociedade moderna dividida entre os sistemas funcionais e o mundo da vida.

"Soberania popular como procedimento" foi escrito com o propósito de descrever qual herança da Revolução Francesa ainda permanece atual por ocasião de seu bicentenário. Habermas começa expondo uma série de consequências importantes da grande Revolução, que, contudo, considera superadas no curso da história e afirma que unicamente necessita ainda ser resolvida a disputa entre direitos humanos e soberania popular. Desde o século XVII, os pensadores dividiram-se em duas grandes concepções rivais acerca das questões políticas; por um lado, os liberais entenderam que a própria pessoa é portadora de determinados direitos relativos a sua liberdade subjetiva de ação e válidos independentemente da estrutura política. Estes direitos subjetivos fundamentais, ou direitos humanos, devem ser institucionalizados, posteriormente, por meio do estado de direito e protegidos contra as intromissões de outras pessoas, bem como as do próprio estado de direito. Por conseguinte, ao menos a parte do ordenamento jurídico concernente aos direitos fundamentais deve ser blindada contra a vontade, muitas vezes irracional e arbitrária, da maioria, o que constitui a ideia do império da lei. Por outro lado, os republicanos consideram que qualquer um que legisle em nome de outro pode cometer uma injustiça contra ele, por isso somente o povo unido, ao legislar, jamais pode cometer injustiça contra si mesmo; portanto, os direitos devem decorrer exclusivamente da soberania popular, neles incluídos os direitos humanos, pois o povo democraticamente reunido jamais legislaria contra os seus direitos fundamentais. A soberania popular exige, todavia, uma virtude política por parte dos cidadãos que precisa ser compensada mediante a coerção legal quando os países são muito grandes ou falta uma unidade de costumes, e, portanto, não se cumprem as condições de uma cidadania ativa. 
Essa disputa recorrente entre direitos humanos e soberania popular assenta-se no legado da filosofia da consciência, porque os liberais fundamentam os direitos humanos no sujeito privado (Locke, por exemplo, considera que o homem foi criado por Deus com determinados direitos naturais, e Kant obtém os direitos subjetivos com base na autonomia do sujeito moral), enquanto os republicanos interpretam o povo (a comuna ou a assembleia) como um sujeito em grande escala. Habermas considera que somente um conceito procedimental de soberania popular, sem os pressupostos da filosofia do sujeito, pode pôr fim a essa disputa e reconhecer o caráter cooriginário dos direitos humanos e da soberania popular.

O princípio procedimental de soberania popular representa, para o estado de direito, o mesmo papel que o princípio da democracia representa para o sistema de direitos. Assim como o princípio da democracia serve de dobradiça entre a autonomia privada e a autonomia pública, dado que, sob as condições do discurso jurídico, submetido simultaneamente à exigência do entendimento e da forma jurídica, os cidadãos têm de se atribuir reciprocamente, segundo a gênese lógica dos direitos, os direitos subjetivos fundamentais que garantem as liberdades individuais, bem como os direitos políticos de participação e comunicação, o princípio da soberania popular permite a mediação entre os direitos subjetivos fundamentais e o direito objetivo instituído pelo estado de direito, porque a fundamentação do direito objetivo tem de pressupor a fundamentação simultânea dos direitos subjetivos, uma vez que somente cidadãos portadores de direitos subjetivos fundamentais podem participar em discursos de fundamentação dos princípios do estado de direito (HABERMAS, 1994, p. 209).

O princípio procedimental da soberania popular, consequentemente, supera a imagem republicana da autogestão democrática dos cidadãos reunidos em assembleia e capazes de chegar a uma vontade comum, que é incompatível com as condições da sociedade complexa dividida em sistemas funcionais. Em lugar de localizar a soberania popular no povo entendido como um macrossujeito, ele prefere difundi-la por meio do intercâmbio entre as redes informais de comunicação da esfera pública e as instituições formais do estado de direito, com o objetivo de produzir uma figura política anônima ou carente de sujeito (HABERMAS, 1994, p. 208-9).

A soberania popular, segundo a teoria discursiva, surge inicialmente com base na liberdade comunicativa dos cidadãos no mundo da vida, que consiste na capacidade para chegar ao entendimento, implícita na ação comunicativa cotidiana. Os sujeitos dotados de liberdades subjetivas de ação podem entrar em conflito entre si, porém, a liberdade comunicativa inerente à ação comunicativa permite que cheguem a um acordo sobre as questões controvertidas. 
Os problemas que podem surgir na ação comunicativa são de dois níveis: no primeiro nível, pode ser problematizada a interpretação da ação com base em valores ou normas previamente dados, enquanto, no segundo, os próprios valores ou normas de ação são postos sob suspeita. No primeiro nível, a reflexividade da linguagem ordinária permite que os sujeitos cheguem a um entendimento sobre a interpretação correta dentro da própria ação comunicativa, porém, no segundo, exige que se suspenda a ação e eles entabulem os discursos práticos de fundamentação, nos quais somente são válidos os melhores argumentos.

Os discursos práticos podem ser pragmáticos, éticos ou morais. Os discursos pragmáticos avaliam programas coletivos de ação, os discursos éticos investigam quais valores podem merecer o reconhecimento dos participantes, enquanto os discursos morais examinam quais normas de ação são corretas na medida em que podem ser do interesse simétrico de todos os implicados. Existem também as negociações sobre interesses submetidas a condições equitativas. A liberdade comunicativa dos sujeitos, produzida na ação comunicativa ou nos discursos práticos, bem como as negociações sob condições equitativas servem-se das redes de comunicação da esfera privada, podem permitir a formação da opinião pública dos cidadãos na esfera pública e chegar a ser institucionalizadas nos discursos jurídicos, bem como nas instituições do estado de direito.

Habermas considera que esse conceito procedimental de soberania popular, que permite a institucionalização da liberdade comunicativa dos cidadãos, pode ser reconstruído também com base na teoria do poder desenvolvida sobre as reflexões republicanas de Hannah Arendt (HABERMAS, 1994, p. 182-3). Hannah Arendt contrapõe poder e violência. Por poder, entende a força geradora de consenso de uma comunicação orientada ao entendimento, enquanto, por violência, compreende a capacidade de instrumentalização da vontade de outros para fins alheios. O poder puro manifesta-se nos movimentos revolucionários, quando os cidadãos saem espontaneamente à rua e forjam novas constituições, enquanto a violência aparece tão logo o governo constitui-se por meio das instituições ordinárias da política (HABERMAS, 1994, p. 183-4). Em lugar da imagem republicana encontrada em Hannah Arendt, que localiza o poder no povo ou nas assembleias populares, Habermas reconstrói os conceitos de poder e violência de acordo com sua teoria da ação comunicativa por meio da figura desprovida de subjetividade de uma sociedade civil acostumada à liberdade, cujos cidadãos podem formar a opinião e a vontade na esfera pública fazendo uso de sua liberdade comunicativa mediante a capacidade de chegar ao entendimento que os cidadãos dispõem no mundo da vida.

Com base nessa perspectiva intersubjetiva surgem três conceitos diferentes de poder: poder comunicativo, poder administrativo e poder social. 
O poder comunicativo constitui-se mediante os meios discursivos dispersos de uma opinião pública que pode chegar a um consenso sobre metas políticas em discursos pragmáticos, valores compartilhados em discursos éticos ou normas de ação em discursos morais, assim como sobre seus interesses em negociações equitativas. Este poder comunicativo, que surge discursivamente nas instâncias da opinião pública, tem de penetrar nas estruturas do estado de direito de tal modo que possa orientar as ações do poder administrativo (HABERMAS, 1994, p.183).

O poder administrativo consiste na substituição da violência, que os indivíduos possuem em estado natural, pela violência organizada do estado civil, permite a constituição das instâncias do estado de direito, a legislação, o governo e a justiça como uma ordem legal e, por fim, estabelece faculdades e competências que autorizam o estado de direito a tomar decisões vinculantes. Com a subordinação do poder administrativo do estado de direito ao poder comunicativo dos cidadãos, as instituições do estado de direito amoldam-se às condições normativas da autolegislação; isso, porém, somente pode ocorrer porque o direito funciona como meio de transformação do poder comunicativo em administrativo, uma vez que, do ponto de vista do sistema político, o consenso que se gera discursivamente e as razões que se aduzem a favor das leis continuam sendo interpretados, pela óptica do poder, como resultado do conflito entre interesses divergentes. O sistema político não considera a possibilidade de um entendimento autêntico entre os cidadãos. Portanto, os argumentos que comprovam a legitimidade das leis aparecem, para ele, como a racionalização de decisões tomadas previamente com base em posições de poder. Não é a razão que fundamenta a tomada de decisão, mas é a tomada de decisão que tem de justificar-se por meio de argumentos que diminuem o grau de surpresa da deliberação ou da sentença (HABERMAS, 1994, p. 186-7).

Por último, na esfera da opinião pública, também pode surgir o poder social, que mede a possibilidade de um agente impor seus próprios interesses nas relações sociais, até mesmo contra a resistência dos demais (HABERMAS, 1994, p. 215); este poder nasce pela pressão que exercem os grupos de interesses para influenciar a legislação, o governo e a justiça. Habermas entende que o poder social compete com o poder comunicativo pela influência sobre o poder administrativo, porém, apesar de que o poder social pode tanto representar os interesses de grandes grupos econômicos, vir manipulado pela publicidade e pelos meios de comunicação, por um lado, ou dar expressão a interesses generalizáveis, a exemplo das questões ecológicas ou sociais fomentadas pelas organizações não governamentais, por outro, tem que ser neutralizado quando se considera a perspectiva normativa da legislação (HABERMAS, 1994, p. 186-7). 
Com base na teoria do poder é possível explicar o princípio procedimental da soberania popular. Todo poder político tem de emanar do poder comunicativo que surge da liberdade comunicativa dos cidadãos, os quais são capazes de chegar ao entendimento no mundo da vida por meio da reflexividade inerente à ação comunicativa ou dos discursos práticos de fundamentação de programas coletivos de ação, valores compartilhados e normas morais, além das negociações sob condições equitativas. Este poder comunicativo tem de penetrar nas instituições do estado de direito, que se tornou, por sua vez, sensível às reivindicações procedentes do poder comunicativo dos cidadãos, e converter-se em poder administrativo, sem interferir na lógica própria do sistema político que permanece regida pelo poder administrativo. Por fim, o estado de direito tem de neutralizar a influência do poder social, de modo que somente as pretensões legítimas dos cidadãos, mediadas pela formação da opinião e a vontade na esfera pública, possam se converter em poder administrativo (HABERMAS, 1994, p.187).

A transformação do poder comunicativo em poder administrativo somente pode ocorrer por causa da tensão interna entre direito e política dentro do estado de direito. O sistema político é um sistema funcional especializado no uso instrumental do poder administrativo, enquanto o direito permite a institucionalização do poder comunicativo gerado pelos cidadãos. Habermas observa, contudo, que esta tensão interna nem sempre reflete um intercâmbio equilibrado entre direito e política. Nas sociedades tradicionais, o direito exercido burocraticamente pelo príncipe era fundamentado metafisicamente na lei eterna de Deus, assim como empiricamente nos costumes seculares, o que conferia legitimidade ao direito positivo. Com o surgimento da modernidade, o direito natural racional substituiu a legitimidade proveniente do direito divino pela razão natural, mas deixou claro que o direito poderia servir tanto para a institucionalização das liberdades fundamentais do indivíduo ou da vontade soberana dos cidadãos como para conferir legalidade ao uso instrumental do poder político (HABERMAS, 1994, p. 180-1). O equilíbrio entre o código instrumental do poder político e o código normativo do direito voltou a ser ameaçado pelo Estado do bem-estar social, na medida em que, em lugar de institucionalizar o poder comunicativo dos cidadãos, o direito possibilitou a intromissão burocrática no mundo da vida das pessoas privadas. A experiência do Estado do bem-estar mostrou que o poder administrativo do estado de direito, mais que institucionalizar o poder comunicativo dos cidadãos, possui uma tendência à autoprogramação, a qual se verifica na escolha de programas de ação independentemente da participação dos cidadãos (HABERMAS, 1994, p. 622).

Para mostrar como o poder comunicativo pode transformar-se em poder administrativo e evitar a autoprogramação do sistema político, Habermas fundamenta os princípios do estado de direito com base no princípio 
da soberania popular reconstruído intersubjetivamente de acordo com a teoria do discurso (HABERMAS, 1994, p. 209).

Do ponto de vista normativo, o poder comunicativo deve ser gerado pela totalidade dos cidadãos sobre a base do uso de suas liberdades comunicativas no mundo da vida; a versão procedimental da soberania popular não exige, porém, que os cidadãos se organizem diretamente em assembleias populares, mas que ela flua ao longo de toda a sociedade. Além do mais, do ponto de vista sociológico, seria pouco realista esperar que os cidadãos possam reunir-se para deliberar na sociedade complexa dividida em sistemas funcionais. Portanto, como a soberania popular não pode ser localizada em nenhum lugar ou sujeito privilegiado, Habermas considera que é indispensável garantir um amplo espaço de participação para os cidadãos no plano da sociedade civil no que se refere à apresentação de temas e contribuições com a finalidade de formar a opinião e a vontade sobre matérias capazes de constituir-se em lei por meio dos discursos práticos que demandam a livre circulação de informações e razões. Essa exigência é institucionalizada pelo princípio do pluralismo político e pelo princípio da competição entre partidos, que permite a cada cidadão sustentar sua posição política, assim como pelo princípio da garantia de espaços públicos autônomos, que possibilita a livre formação da opinião pública sem a manipulação dos grandes grupos de interesses e do próprio estado de direito (HABERMAS, 1994, p. 211). Por outro lado, os cidadãos, na sociedade civil, podem formar a opinião e a vontade por meio dos discursos práticos e das negociações sob condições equitativas, porém, não podem organizar-se para deliberar, o que torna necessário introduzir o princípio parlamentar, que possibilita instituir corpos legislativos encarregados de tomar decisões.

A lei obtida nos discursos de deliberação e tomada de decisão dos corpos legislativos, evidentemente, constitui o parâmetro para a ação dos sujeitos jurídicos com respeito a outros sujeitos jurídicos e ao próprio estado de direito, o que implica a possibilidade de ser acionada judicialmente para a garantia da liberdade subjetiva de ação por intermédio do princípio de proteção dos direitos individuais. Por outro lado, a aplicação da lei demanda também a capacidade jurídica de impor a sentença mediante os instrumentos repressivos do Estado, o que dota a instância judicial de poder administrativo. Como o poder administrativo possui uma tendência à autoprogramação, é indispensável garantir a segurança jurídica por meio do princípio de vinculação da justiça ao direito vigente (HABERMAS, 1994, p. 212-3).

Habermas está particularmente preocupado pelo fato de que o executivo pode programar-se a si mesmo, submetendo os cidadãos a seus decretos, normas e portarias, em lugar de refletir a conversão do poder comunicativo em administrativo, por isso, considera que somente o princípio da legalidade do governo expressa o núcleo da divisão de poderes. Com base 
na teoria discursiva do poder, a constituição de poderes separados dentro do estado de direito tem como finalidade garantir que o poder administrativo reproduza o poder comunicativo gerado pelos cidadãos. O poder executivo, dentro do estado de direito, tornou-se especializado em institucionalizar discursos pragmáticos que definem as condições técnicas e organizacionais para implementar os programas de ação. Da mesma maneira que o poder judicial, o executivo dispõe de poder administrativo. Portanto, a estrita vinculação do executivo à lei produzida pelo legislativo evita que o governo possa determinar as condições para tomar decisão e, consequentemente, implica que o poder administrativo não possa intervir nos processos de produção e aplicação do direito (HABERMAS, 1994, p. 213).

A legislação e a justiça podem empregar poder administrativo na medida em que este lhes serve exclusivamente como uma condição de possibilidade para institucionalizar os discursos práticos (discursos de fundamentação de normas jurídicas no caso do legislativo e de aplicação para o judiciário), porém, o executivo só pode dispor de funções administrativas, pois, em caso contrário, acaba submetendo a legislação e a justiça a condições restritivas que estorvam os procedimentos comunicativos inerentes aos discursos legislativos e jurídicos, dando lugar à perda da legitimidade das leis e sentenças judiciais. Portanto, a permissão para o emprego do poder administrativo por parte do executivo exige uma harmonia de poderes que Habermas denomina princípio de proibição da ilegalidade dentro do Estado (HABERMAS, 1994, p. 214).

Por último, Habermas introduz um princípio de separação entre o estado e a sociedade. Esta separação normalmente é interpretada segundo o paradigma do Estado liberal e faz parte da estratégia de defesa da esfera de liberdade subjetiva de ação para os sujeitos privados por meio de direitos fundamentais protegidos contra outros sujeitos privados e contra a intromissão do Estado, que garantem o desenvolvimento de um sistema econômico regido pelo automatismo da livre competição. Com base na perspectiva discursiva, contudo, a separação entre Estado e sociedade permite o florescimento de uma população acostumada à liberdade e à prática da comunicação na esfera pública, sobretudo porque o poder comunicativo é um bem escasso, que não se pode reproduzir à vontade pelo Estado, como ficou comprovado com o fracasso do socialismo de Estado em tentar manipular os cidadãos. Uma sociedade civil, capaz de organizar-se, permite a fluidificação da soberania popular entre o espaço informal da opinião pública e as instituições porosas do estado de direito (HABERMAS, 1994, p. 215).

Além do mais, a separação entre o Estado e a sociedade tem como finalidade permitir que o poder social dos grandes grupos de interesse possa ser neutralizado, tanto no seio da própria esfera pública, como nas instituições do estado de direito e, assim, determinar o poder administrativo. O po- 
der social pode produzir-se de formas muito distintas; em primeiro lugar, os grandes grupos econômicos podem pressionar diretamente o legislativo para aprovar leis favoráveis ou o governo para implementar programas de ação, porém, em geral, prefere manipular a opinião pública através da publicidade possibilitada pelos meios de comunicação; por outro lado, o poder social pode ser exercido pelos próprios cidadãos com o propósito de permitir a influência do poder comunicativo sobre as instâncias do estado de direito quando estas se mostram especialmente insensíveis. Habermas considera que a separação entre Estado e sociedade possibilita impedir que o poder social possa transformar-se em poder administrativo e transformar o próprio Estado em um partido entre outros, como ocorre quando o Estado representa predominantemente os interesses de um grupo (HABERMAS, 1994, p. 216). A tese da neutralidade do Estado, segundo a qual o Estado deve superpor-se aos interesses particulares provenientes da sociedade civil, sempre representou uma ideologia. Ao pretender, contudo, que o estado de direito anule o poder social, Habermas não está retrocedendo à tese da neutralidade do Estado, porque o estado de direito não pode ser neutro com respeito ao poder comunicativo gerado discursivamente pelos cidadãos (HABERMAS, 1994, p. 216).

O princípio procedimental de soberania popular permite também fundamentar o princípio da divisão de poderes no estado de direito. A teoria clássica da divisão de poderes provém do liberalismo e, segundo Habermas, fundamenta-se em um conceito restringido de lei, pois define a lei em termos semânticos. A legitimidade da lei não emana do procedimento democrático, mas de sua forma gramatical, na medida em que o caráter geral e abstrato em que se formulam as proposições normativas garante que todos sejam iguais perante a lei. Por conseguinte, a divisão de poderes pode ser explicada com base em uma lógica da subsunção que opera com a ideia de inclusão de uma classe em outra. Como os conteúdos normativos das leis constitucionais são mais gerais que as leis ordinárias, as quais, por sua vez, são mais gerais que os decretos, a divisão de poderes pode ser explicada pela subordinação das medidas administrativas do executivo à lei ordinária e da lei ordinária à lei constitucional, aplicadas pelo judiciário e aprovadas pelo legislativo (HABERMAS, 1994, p. 232-3).

De acordo com a versão procedimental do princípio da soberania popular, contudo, a lei não pode ser entendida semanticamente com base em sua forma gramatical, mas pragmaticamente com base nos procedimentos democráticos de sua produção. A lei é o resultado da tomada de decisão dos corpos legislativos, na medida em que estes representam a institucionalização jurídica dos discursos práticos e das negociações sob condições equitativas, implementadas pelos próprios cidadãos que formam a opinião e a vontade na esfera pública. Nestes discursos informais da esfera pública e 
formais do sistema político ocorre uma fusão de razão e vontade, pois, as condições procedimentais que permitem avaliar a validade da lei também formam a convicção dos participantes.

Então, a concepção procedimental do princípio da soberania popular determina a fundamentação da divisão de poderes do estado de direito não com base na lógica da subsunção da lei particular sob a lei geral, mas baseada na lógica do discurso, o que implica que a separação entre o poder legislativo, enquanto instância legisladora, o poder judicial, como instância aplicadora, e o poder executivo, como instância executora, resulta da distribuição de possibilidades de recorrer às distintas classes de razões e formas de comunicação apropriadas a estas classes de razões.

O poder legislativo é o único que dispõe de todo o espectro de razões e formas de comunicação correspondentes desenvolvidas com base na perspectiva de fundamentação das normas de ação. O legislativo elabora discursivamente as questões pragmáticas, éticas e morais além das negociações sob condições equitativas, com a finalidade de fundamentar as respectivas normas de ação. A justiça também dispõe de todas as classes de razão e formas de comunicação, porém com base na perspectiva dos discursos de aplicação que permitem chegar à sentença consistente, submetida à coerência do ordenamento jurídico. Por fim, o executivo limita-se às questões e discursos pragmáticos que definem os programas de ação dentro do marco da lei e opera segundo a racionalidade estratégica na escolha de tecnologias e processos para a realização mais eficiente de seus fins (HABERMAS, 1994, p. 235-6).

De acordo com a lógica da argumentação, portanto, o legislativo, em sintonia com a comunicação política dos cidadãos na esfera pública, encarrega-se dos discursos de fundamentação, enquanto o poder judiciário institucionaliza os discursos de aplicação de normas, segundo o princípio da adequação apresentado por Klaus Günther. A diferença entre discursos de fundamentação e discursos de aplicação implica uma estrutura de comunicação distinta nos âmbitos do legislativo e do judiciário. Nos discursos legislativos de fundamentação, somente há participantes orientados pela busca cooperativa do entendimento sobre a validade das normas de ação, enquanto nos discursos jurídicos de aplicação, há uma diferenciação de papéis entre os representantes das partes litigantes, que oferecem distintas perspectivas sobre os fatos, assim como sobre sua interpretação, perante o juiz que, por outro lado, assume a função de representante imparcial da comunidade jurídica e precisa justificar a sentença ante um espaço público jurídico composto por membros da magistratura, profissionais do direito e cidadãos em geral, enquanto membros da comunidade aberta dos intérpretes da constituição. A argumentação jurídica não tem o sentido da busca cooperativa do entendimento, uma vez que cada uma das partes tem o de- 
ver de defender os interesses de seus clientes no processo civil ou os papéis de acusação e defesa no processo penal, porém, do ponto de vista do juiz, a contenda entre as partes, com a consequente apresentação de provas (que somente encarnam elementos dos argumentos), serve para a reconstrução das normas e fatos correspondentes com a finalidade de chegar à descrição mais adequada e completa para o caso dado, com base nas leis mais pertinentes, de modo que seja prolatada a sentença (HABERMAS, 1994, p. 212-3).

As negociações sob condições equitativas e os discursos práticos pressupõem, evidentemente, uma série de idealizações, específicas para cada caso. A teoria da argumentação demanda que os participantes nos discursos práticos, no plano lógico-semântico, por exemplo, não se contradigam, não atribuam predicados diferentes para um mesmo sujeito da proposição e não usem uma mesma expressão em sentidos diferentes; no plano procedimental, que sejam sinceros em suas declarações e somente ponham em dúvida uma norma que aparentemente não seja susceptível de aprovação, dando razões para isto, assim como, no plano pragmático, que exige a participação de todo sujeito capaz de comunicar-se, permitam a problematização de qualquer norma relevante e não impeçam coercitivamente a expressão de ninguém (HABERMAS, 1996, p. 97-9).

Consequentemente, essas idealizações inerentes aos pressupostos comunicativos dos discursos práticos somente podem ser realizadas de modo aproximado, porque, por um lado, a argumentação tem de prosseguir até que todos os implicados pela entrada em vigor da norma possam aceitá-la e, por outro, como não existe um critério independente do procedimento para determinar a validade do resultado, isto implica a possibilidade de retomar-se constantemente a avaliação das normas em função de novas informações e razões. Portanto, os exigentes pressupostos da argumentação racional envolvem um momento de falibilismo que é incompatível com a necessidade de tomar decisão das instituições do estado de direito. Por isso, Habermas observa que a institucionalização das negociações sob condições equitativas e os discursos práticos nos procedimentos jurídicos implica a introdução de restrições relativas a aspectos temporais, sociais e de conteúdo aos quais eles não estão inicialmente submetidos; sua inserção, porém, nos discursos jurídicos do estado de direito tem que deixar intacta a lógica própria dos discursos práticos (HABERMAS, 1994, p. 219-20).

Dois exemplos de limitações institucionais provenientes da institucionalização jurídica das negociações sob condições equitativas e dos discursos práticos são a regra da maioria, assim como a forma dos mandatos e composição do sistema representativo.

Os discursos jurídicos realizados pelos corpos legislativos e os tribunais colegiados têm que interromper as negociações e discussões por causa da necessidade de adotar uma decisão de acordo com regras e prazos. A regra 
da maioria justifica-se, por um lado, pela pressão institucional para tomar-se uma decisão, porém, por outro lado, porque estes discursos podem prosseguir no futuro e possibilitar que as minorias convertam-se em novas maiorias, por meio do convencimento das antigas maiorias (HABERMAS, 1994, p. 219).

A ideia procedimental de soberania popular, por outro lado, implica que a forma do mandato e a composição dos parlamentos dependam do tipo de razões e formas de comunicação correspondentes a cada caso. As negociações sob condições equitativas determinam que os representantes sejam escolhidos para negociar compromissos, o que exige que todos os interesses e preferências axiológicas possam contar com o mesmo peso. Como nas negociações os interesses e valores estão previamente fixados, não pode haver nenhuma diferença entre a vontade popular empírica e a vontade popular hipotética, o que define os mandatos como imperativos (HABERMAS, 1994, p. 222-3).

Os discursos éticos e morais, por outro lado, não pressupõem posições dadas de antemão, mas um intercâmbio entre os cidadãos que constituem a opinião pública e seus delegados nos corpos legislativos, pois os interesses e preferências de valores podem modificar-se discursivamente através do fluxo de informações e razões (HABERMAS, 1994, p. 223). Os discursos éticos, por exemplo, estão orientados para a busca da autenticidade, e permitem que os implicados possam chegar ao autoentendimento a respeito de sua própria forma de vida, o que possibilita tanto a crítica como o fortalecimento da identidade coletiva. Portanto, nos discursos de autoentendimento não pode haver não-implicados, pois todos os membros do coletivo devem poder participar do discurso. Apesar de que motivos técnicos obrigam a que esses discursos realizem-se por meio de representantes, eles têm de satisfazer à condição de participação de todos os membros por igual, o que demanda serem os deputados abertos e sensíveis às informações e razões que brotam da opinião pública dos cidadãos (HABERMAS, 1994, p. 223-4).

Os discursos morais, por fim, permitem que os participantes cheguem a um acordo sobre a validade das normas de ação que possam ser do interesse simétrico de todos. Assim como nos discursos éticos, a forma de escolha dos delegados deve assegurar a inclusão de todas as perspectivas relevantes, a qual também se pode modificar em função das informações e razões apresentadas discursivamente, que, por isso, requerem dos representantes sensibilidade para os fluxos de comunicação que emanam da esfera pública; ao contrário, contudo, dos discursos éticos de autoentendimento, o conjunto dos implicados não se limita somente aos membros de uma comunidade particular, mas a todos os seres humanos em geral, o que obriga a uma composição de delegados capazes de distanciar-se, até mesmo, do etnocentrismo de sua forma especial de vida (HABERMAS, 1994, p. 224-5). 
DURÃO, Aylton Berbieri. Habermas: foundations of the democratic state of law. Trans/Form/Ação. São Paulo, v.32(1), 2009, p.119-137.

- ABSTRACT: The democratic rule of law is constituted by means of the internal tension between law and politics because, besides its own functions, since law must regulate interpersonal or collective conflicts of action while politics must carry out collective programs of action, each one must perform reciprocal functions concerning the other, since politics, as an instrumental pole, must provide juridical norms with the capacity of coaction, while law, as a normative pole, must lend its own legitimacy to political decisions. For the foundation of the principles of the rule of law an inter-subjective reconstruction of popular sovereignty is necessary based on the theory of discourse according to which sovereignty is not localized in any concrete subject, but is dispersed in the broad net of communication that underlies the public sphere, where the communicative power is formed, being capable to neutralize the social power of pressure groups and form a public opinion that orientates decision making and the administrative power of the rule of law institutions.

- KEYWORDS: Habermas; law; politics; discourse; power.

\section{Referências bibliográficas}

BAYNES, K. The Normative Grounds of Social Criticism. Kant, Rawls and Habermas. Albany (NY): SUNY, 1992.

Democracy and the Rechtsstaats: Habermas's Faktizität und Geltung. Cambridge Companion to Habermas. Cambridge: Cambridge University Press, 1995. p. 201-32.

BOHMAN, J. "Complexity, Pluralism, and the Constitutional State: On Habermas's Faktizität und Geltung". Law and Society Review, s. 1., 28(4): 897-930, 1994.

Public Deliberation. Pluralism, Complexity, and Democracy. Cambridge (Mass): MIT, 1996.

COHEN, J. L. \& ARATO, A. Civil Society and Political Theory. Cambridge (Mass): MIT, 1997.

CRONIN, C. P. Translator's Introduction. Justification and Application. Cambridge (Mass)/Londres: MIT, 1993. p. XI-XXXI.

GIMBERNAT, J. A. (Org.). La filosofía moral y política de Jürgen Habermas. Madri: Biblioteca Nueva, 1997.

HABERMAS, J. Legitimationsprobleme im Spätkapitalismus. Frankfurt am Main: Suhrkamp, 1973. . Eine Art Schadensabwicklung. Kleine politische Schriften VI. Frankfurt am Main: Suhrkamp, 1987.

Faktizität und Geltung. Beitrage zur Diskurstheorie des Rechts und des demokratischen Rechtsstaats. 4. ed. Frankfurt am Main: Suhrkamp, 1994. 
HABERMAS, J. Theorie des Kommunikativen Handelns. Frankfurt am Main: Suhrkamp, 1995.

Zur Rekonstruktion des Historischen Materialismus. 6. ed. Frankfurt am Main: Suhrkamp, 1995.

Moralbewußtsein und Kommunikatives Handeln. 6. ed. Frankfurt am Main, Suhrkamp, 1996.

Die Einbeziehung des Anderen. Studien zur politischen Theorie. 2. ed. Frankfurt am Main: Suhrkamp, 1997.

PINZANI, A. \& DUTRA, D. V. Habermas em discussão. Florianópolis: Nefipo, 2005. $222 \mathrm{p}$.

REHG, W. Translator's Introduction. Between Facts and Norms. Contributions to a Discourse Theory of Law and Democracy. Trad. de William Rehg. Cambridge (Mass): MIT, 1996. p. IX-XXXVII.

SIEBENEICHLER, F. B. A justiça como inclusão do outro. Ethica: Cadernos Acadêmicos, Rio de Janeiro, v. 8, n. 2, 2001.

VELASCO, J. C. La teoría discursiva del derecho. Sistema jurídico y democracia en Habermas. Madri: Centro de Estudios Políticos y Constitucionales, 2000. 